\title{
Comparison of Aspiration versus Stent Retriever Thrombectomy as the Preferred Strategy for Patients with Acute Terminal Internal Carotid Artery Occlusion: A Propensity Score Matching Analysis
}

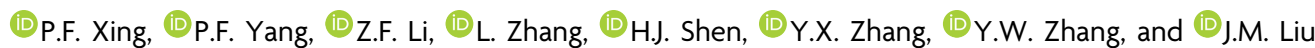

\begin{abstract}
BACKGROUND AND PURPOSE: There is no consensus on endovascular treatment for terminal ICA. The purpose of this study was to evaluate the comparative safety and efficacy of preferred aspiration thrombectomy and stent retriever thrombectomy for revascularization in patients with isolated terminal ICA occlusion.
\end{abstract}

MATERIALS AND METHODS: We conducted a retrospective analysis of patients with terminal ICA occlusion treated with aspiration thrombectomy or stent retriever thrombectomy in our center, from September 2013 to November 2018. To minimize the case bias, propensity score matching was performed. The primary outcomes were successful reperfusion defined by expanded TICl grades $2 \mathrm{~b}-3$ at the end of all endovascular procedures and puncture-to-reperfusion time.

RESULTS: A total of 109 consecutive patients with terminal ICA occlusion were divided into the aspiration thrombectomy group (40 patients) and the stent retriever thrombectomy group (69 patients), and 30 patients were included in each group after propensity score matching. The proportion of complete reperfusion was significantly higher in the aspiration thrombectomy group (OR $4.75[95 \% \mathrm{Cl}, 1.10-1.38] ; P=.002$ ). The median puncture-to-reperfusion time in the aspiration thrombectomy group was shorter than that in the stent retriever thrombectomy group (38 versus 69 minutes; $P=.001$ ). Fewer intracerebral hemorrhage events were recorded in the aspiration thrombectomy group (OR $0.29[95 \% \mathrm{Cl}, 0.09-0.90] ; P=.028)$. No significant differences were observed for good outcomes (OR 1.92 [95\% Cl, 0.86-4.25]) and mortality (OR 0.84 [95\% Cl, 0.29-2.44]) at 90 days.

CONCLUSIONS: For the treatment of terminal ICA occlusion, aspiration thrombectomy was technically superior to stent retriever thrombectomy in the absence of a balloon guide catheter in achieving successful reperfusion with shorter puncture-to-reperfusion time and procedure-related adverse events.

ABBREVIATIONS: ASITN/SIRs = American Society of Interventional and Therapeutic Neuroradiology/Society of Interventional Radiology scale; ASPECTS = Alberta Stroke Program Early CT Score; AT = aspiration thrombectomy; BGC = balloon guide catheter; eTICl = expanded TICl; ICH = intracerebral hemorrhage; ID = internal diameter; PRT = puncture-to-reperfusion time; PSM = propensity score matching; SRT = stent retriever thrombectomy

$\mathbf{T}$ erminal ICA occlusion is a strong predictor of both lower revascularization success and subsequent clinical outcomes, which occur due to a large clot burden, insufficient collateral flow mediated via the contralateral ICA, and new territory emboli

Received October 29, 2019; accepted after revision December 23.

From the Department of Stroke Center, Changhai Hospital, Second Military Medical University, Shanghai, China.

P.F. Xing and P.F. Yang contributed equally to this work.

This study was funded by the Project of Research and Application of Effective Intervention Techniques for High-Risk Stroke Population of China in 2017 (GN2017R0001).

Please address correspondence to Jian-Min Liu, MD, Department of Stroke Center, Changhai Hospital, Second Military Medical University, No. 168 Changhai Rd, Shanghai 200433, China; e-mail: Liul18@vip.163.com

- Indicates open access to non-subscribers at www.ajnr.org

http://dx.doi.org/10.3174/ajnr.A6414 being present during treatment. ${ }^{1-5}$ No consensus has been reached on the preferred endovascular treatment for isolated terminal ICA occlusion that leads to the use of either aspiration thrombectomy (AT) by using a large bore aspiration catheter or stent retriever thrombectomy (SRT). A previous study indicated that AT was useful for rapid clot burden reduction in endovascular therapy for ICA T/L occlusion ( $\mathrm{T}$ or $\mathrm{L}$ indicate the shape of occlusive lesion), and it could facilitate thrombectomy of a large cerebral clot burden. ${ }^{4}$ In contrast to these findings, a retrospective study demonstrated that patients with a higher initial NIHSS score and ICA clot location should be considered for early crossover (manual AT crossed over to stent retriever-mediated AT) or even initial stent retriever-mediated AT for their clots. ${ }^{5}$ The randomized controlled trials, systematic reviews, and metaanalyses previously conducted did not yield consistent 
conclusions with regard to AT and SRT. ${ }^{6-9}$ Most of the patients in these studies had MCA occlusions and the proportion of the patients with a terminal ICA occlusion was lower. Moreover, subgroup analysis based on the occlusion location was not performed, which may have produced different results. The objective of the present retrospective study was to evaluate the comparative safety and efficacy of preferred AT and SRT for revascularization in patients with isolated terminal ICA occlusion by using propensity score matching (PSM) analysis.

\section{MATERIALS AND METHODS Patient Selection}

A retrospective analysis was performed in patients with acute ischemic stroke who were admitted to our center between September 2013 and November 2018. The patients experienced isolated terminal ICA occlusion and were treated by using either AT or SRT within 16 hours of symptom onset. The patients were administered a standard dose $(0.9 \mathrm{mg} / \mathrm{kg})$ of $\mathrm{rtPA}$ if they experienced acute ischemic stroke symptoms within the 4.5-hour time window and in the absence of additional contraindications. The patients who presented with wake-up stroke or with acute ischemic stroke between 6 and 16 hours after symptom onset were included only if the initial infarct size was $<70 \mathrm{~mL}$ and if the mismatch ratio was $\geq 1.8$, as assessed by using RAPID software (iSchemaView, Menlo Park, California), which was based on CT perfusion imaging. ${ }^{10,11}$ The patients with tandem occlusions, severe stenosis (>70\%), missing data, and/or mRS at the 90-day time period were excluded.

\section{Mechanical Thrombectomy Procedure and Grouping}

Balloon guide catheters (BGCs) were not available in our center before 2019. Therefore an 8F VISTA BRITE TIP guide catheter (internal diameter [ID] 0.088 inch, length $90 \mathrm{~cm}$; Cordis, Miami Lakes, Florida) was placed at the ICA ostium for all procedures. The Traxcess 14 (diameter 0.014 inch, length $200 \mathrm{~cm}$; MicroVention, Aliso Viejo, California) microwire, and the Rebar 27 microcatheter (ID 0.027 inch, length $150 \mathrm{~cm}$; Medtronic, Minneapolis, Minnesota) were used in all cases. The $6 \mathrm{~F}$ Navien (ID 0.072 inch, length $125 \mathrm{~cm}$; Medtronic), ACE 64 (distal ID 0.064 inch, length $132 \mathrm{~cm}$; Penumbra, Alameda, California), or 6F Sofia Plus (distal ID 0.070 in, length $125 \mathrm{~cm}$; MicroVention) catheters were used as either intermediate or aspiration catheters in all cases. The Penumbra Pump MAX (Penumbra) and 60-mL syringes (Wego, Weihai, Shandong, China) were used to generate the aspiration force. The Solitaire FR (sizes $6 \times 30 \mathrm{~mm}$ or $4 \times 20 \mathrm{~mm}$; Medtronic), Trevo ProVue (sizes $4 \times 20 \mathrm{~mm}$; Stryker, Kalamazoo, Michigan), or the Revive SE (sizes $4.5 \times$ $22 \mathrm{~mm}$; Codman, Raynham, Massachusetts) were the stent retrievers used in the present study. Visipaque contrast media (GE Healthcare, Piscataway, New Jersey) was used for all patients.

In $\mathrm{AT}$, the intermediate catheter was deployed beyond the surface of the clot by continuous negative pressure aspiration. The microcatheter and microwire were withdrawn synchronously. The time of aspiration from the intermediate catheter with the Penumbra pump was at least 90 seconds in AT before its removal. In SRT, the effective section of the stent retriever was deployed to cover the thrombus and to remain at this position for 3 minutes. However, the aspiration was applied only during stent retriever removal in SRT. Once obvious resistance was applied during stent retriever removal, the stent retriever was not completely withdrawn from the intermediate catheter. The withdrawal was conducted with the intermediate catheter under continuous aspiration. Aspiration was performed to the guide catheter (contacted with a 60 -mL syringe) and to the intermediate catheter (contacted with a connecting tube of Penumbra pump) in the AT and SRT groups synchronously during thrombectomy. The illustrative cases of AT and SRT are shown in Figures 1 and 2 , respectively.

The patients were divided into the AT and the SRT groups based on the initial treatment technique used. The initial treatment technique was based on the physician preference and on the availability of the aspiration catheters at the center. AT was initially selected for cervical ICA pseudo-occlusion. SRT was replaced by AT as rescue treatment when mechanical thrombectomy failed with 3 passes and vice versa. Other rescue strategies, including balloon dilation, stent placement, and glycoprotein IIb/IIIa receptor inhibitor treatment were used when mechanical thrombectomy failed to achieve adequate reperfusion. IV heparin $(0.67 \mathrm{mg} / \mathrm{kg})$ was used routinely from the femoral artery puncture until the end of the procedure for patients without rtPA.

\section{Study Outcomes and Assessments}

The collateral grade before endovascular therapy, including anterior cerebral artery occlusion, was assessed with the American Society of Interventional and Therapeutic Neuroradiology/ Society of Interventional Radiology scale (ASITN/SIRs), which is a 5-point scale (0-4). The primary outcomes were the successful reperfusion (defined as expanded TICI [eTICI] grades 2, 2c, 3) and complete revascularization, defined as eTICI 3 at the end of the angiography. Complete revascularization was accomplished after the end of all endovascular treatments and the termination of the puncture-to-reperfusion time (PRT). The secondary outcomes included optimum functional outcomes, defined as a mRS score of 0-2 at 90 days, successful revascularization rates after the first pass with the first-line technique, a requirement for rescue treatment, 90-day mortality, and procedure-related adverse events. The main procedure-related adverse events were the following: intracerebral hemorrhage (ICH), malignant cerebral edema (brain tissue swelling with mass effect in the absence of hemorrhage), and downstream territory embolism. The latter was defined as new embolism in a downstream territory vessel that was not previously occluded, such as an embolus from the terminal ICA to the MCA M2 segment, or anterior cerebral artery A2 segment.

\section{Statistical Analysis}

The baseline patient demographic information was described with standard descriptive statistics. The outcome data were reported as frequency, mean \pm standard deviation, or median (interquartile range). When applicable, the $\chi^{2}$ test, the rank sum test, and the $t$ test were used to compare the differences between the groups. To reduce data bias and confounding variables, the 

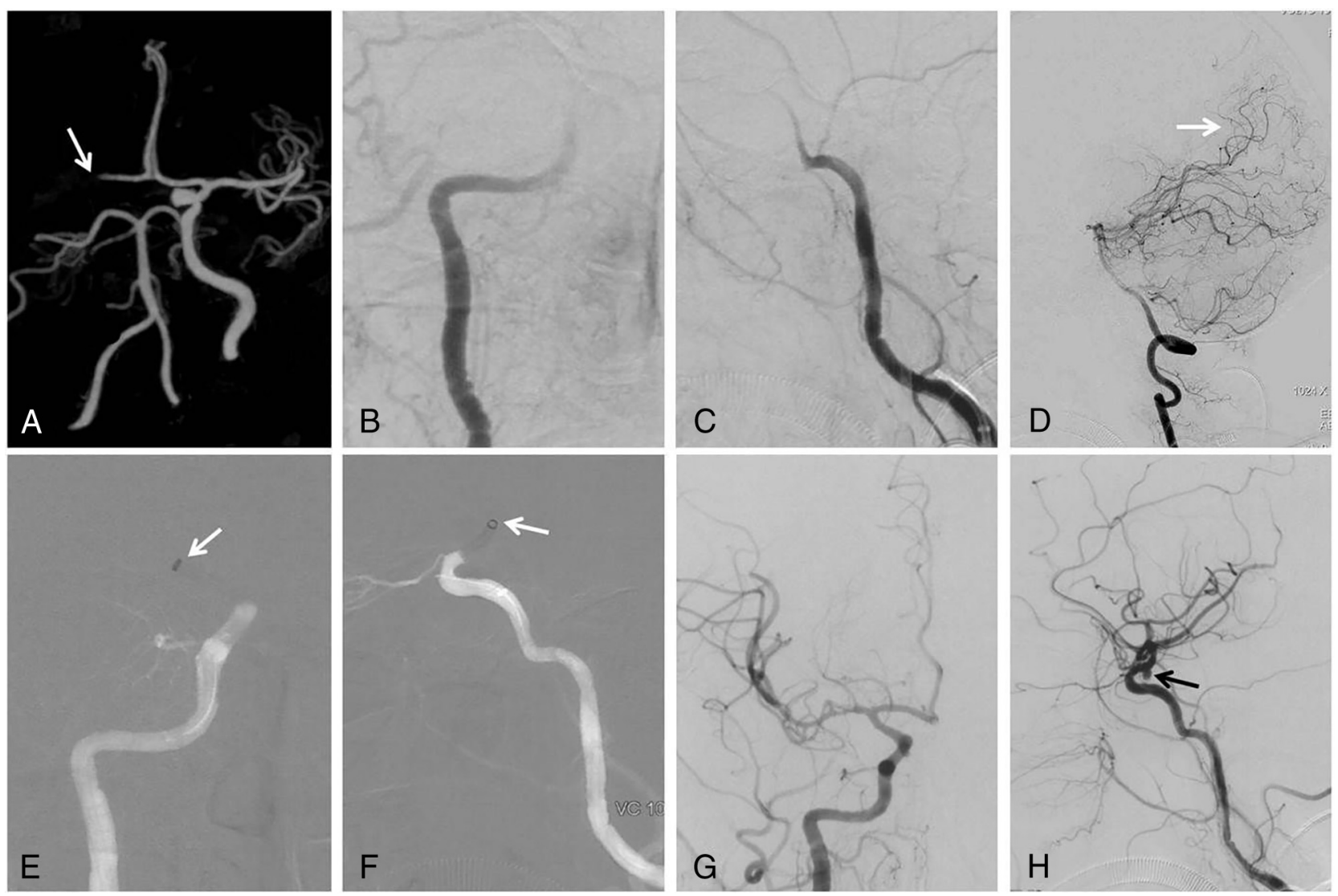

FIG 1. A, AT. Preprocedure CTA of the head indicated that the terminal end of the right ICA was occluded and that the blood flow from the left ICA was supplied to the right anterior cerebral artery and to the ostium of the Al segment (white arrow) through the anterior communicating artery. $B$ and $C$, DSA of the right ICA confirmed that the terminal ICA was occluded. D, A collateral blood supply was present from the posterior cerebral artery to the temporal lobe. $E$ and $F$, A 6 F Sofia Plus $125 \mathrm{~cm}(0.070$ inch) catheter connected to a Penumbra pump was inserted into the terminal ICA via roadmap imaging and was placed beyond the face of the thrombus (white arrows). $G$ and $H$, The ICA was recanalized, with eTICl 3 after 1-pass AT, and a supraclinoid segment aneurysm was present (H, black arrow).

PSM analysis was performed by matching patients in the 2 groups at a 1:1 ratio. The matched variables in the PSM of this study included sex, age, preprocedure NIHSS score, onset to puncture time, and ASITN/SIRs grade. After PSM, the 2 groups were again compared with the aforementioned statistical methods. A $P$ value of $<.05$ was considered as a significant difference. All statistical analyses were conducted with the SPSS software (version 22.0; IBM, Armonk, New York).

\section{RESULTS}

\section{Baseline Characteristics of the Groups}

A total of 109 patients with acute ischemic stroke (mean \pm standard deviation age, $69.1 \pm 11.2$ years; 49 men [45.0\%]) with isolated terminal ICA occlusions met the study inclusion criteria. A total of 40 of the 109 patients $(36.7 \%)$ were treated with preferred AT, whereas the remaining 69 (63.3\%) were treated with preferred SRT. After PSM, 30 cases were included in each group. The baseline characteristics were not significantly different between the groups in the overall sample or in the PSM sample (Table 1) (all $P>.05$ ). The median (interquartile range) preprocedure NIHSS score was 21 (15-23) in the AT group and 19 (16$22)$ in the SRT group $(P=.160)$. The median collateral grades assessed by ASITN/SIRs, the median baseline Alberta Stroke
Program Early CT Score (ASPECTS), and the proportion of ASPECTS $<6$ in the AT and SRT groups were similar for the overall and the PSM samples $(P>.05)$ (Table 1$)$.

\section{Effectiveness of Endovascular Treatment of the Groups}

In the overall sample, the successful revascularization rates in the AT group were significantly higher than those of the SRT group (eTICI 2b-3: OR 1.23 [95\% CI, 1.10-1.38], $P=.002$; eTICI 2c-3: OR 4.62 [95\% CI, 1.72-12.43], $P=.001$; and eTICI 3: OR 3.05 [95\% CI, 1.32-7.06], $P=.008$ ) (Table 2, Figure 3). The median PRT in the AT group was significantly lower than that in the SRT group (46 minutes versus 83 minutes, $P=.001$ ). However, no significant differences were noted between the groups with regard to the first-pass revascularization rates (for eTICI $2 b-3,2 c-3$, or 3 ), the median number of thrombectomy passes, the median time from onset to reperfusion, the proportion of patients who required rescue treatment, the use of rPA, the administration of glycoprotein IIb/IIIa receptor inhibitors, simple balloon angioplasty, stent placement, IV heparin treatment, and an mRS score of $0-2$ at the 90 -day period (all $P>.05$ ) (Table 2).

In the PSM sample, the findings were similar. The proportion of patients in the AT group with an eTICI 2c-3 (OR 6.50 [95\% CI, 1.82-23.21]; $P=.006$ ) and eTICI 3 (OR 4.75 [95\% CI, 

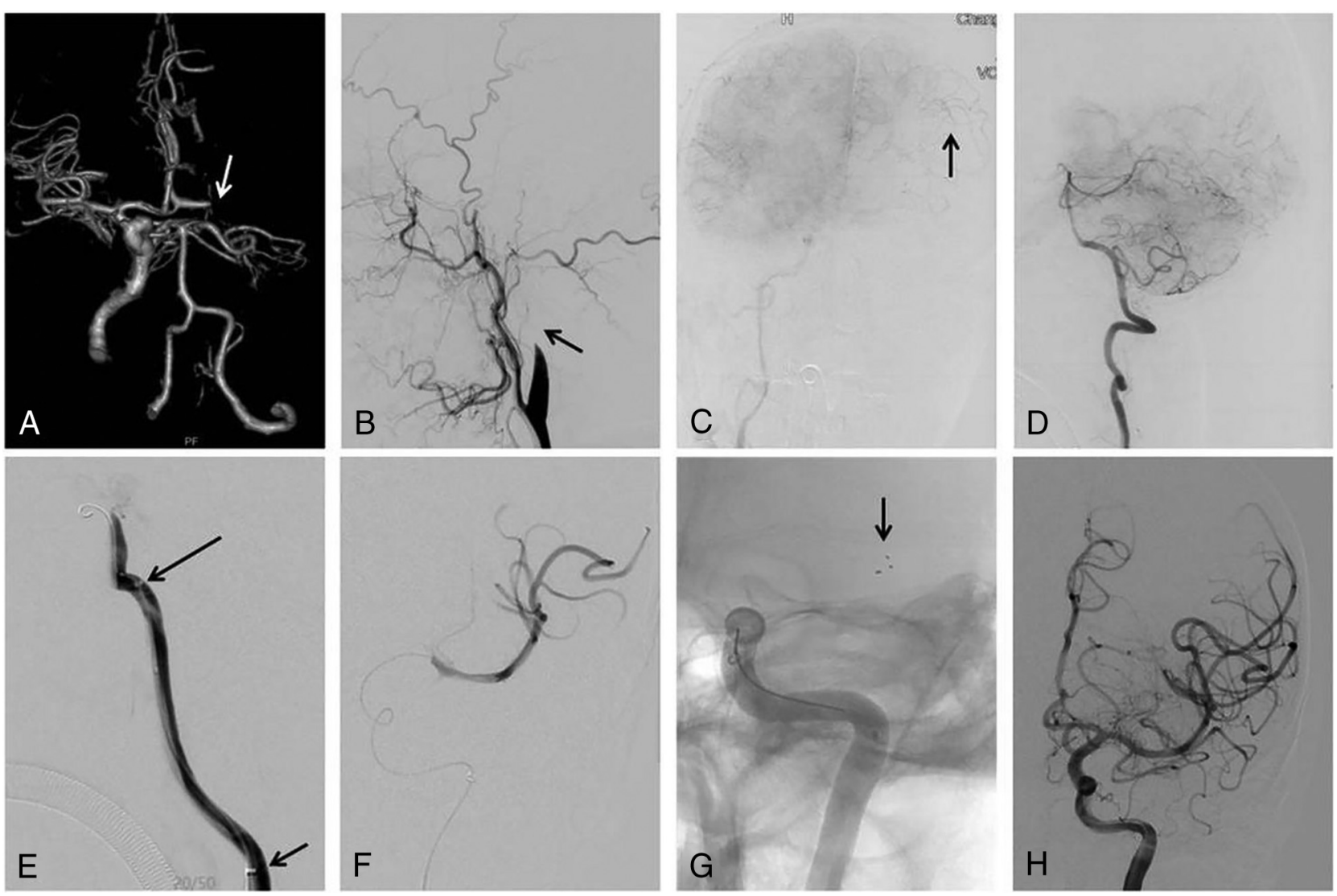

FIG 2. SRT. A, A preprocedure CTA of the head indicated that the terminal end of the left ICA was occluded and that the blood flow from the right ICA was supplied to the left anterior cerebral artery and to the ostium of the Al segment (white arrow) through the anterior communicating artery. B, DSA of the left common carotid artery revealed that the left ICA was occluded (black arrow). C, DSA of the right ICA indicated similar results to $(A)$ CTA, and no collateral blood supply was observed from the $(D)$ posterior to the anterior circulation. E, DSA of the intermediate catheter (long black arrow) and guide catheter (short black arrow) demonstrated that the left carotid terminus was occluded, whereas the cervical ICA was not occluded (pseudo-occlusion) compared with that of image B. F, DSA was performed via the microcatheter crossing the occluded segment and the MCA was patent. G, A Solitaire FR $6 \times 30 \mathrm{~mm}$ stent was used and inserted into the $6 \mathrm{~F}$ Sofia Plus $125-\mathrm{cm}$ catheter, which was advanced closer to the thrombus for local aspiration after the stent-retriever removal. $H$, The ICA was recanalized to eTICI 3 after a 1-pass SRT.

1.58-14.25]; $P=.004)$ was significantly higher than that noted for the SRT group, though the groups did not significantly differ with regard to the parameter eTICI 2b-3 (OR 1.11 [95\% CI, 0.99-1.25]; $P=.237)$. The median PRT was significantly lower in the AT group compared with the SRT group (38 versus 69 minutes,

$P=.001)$, whereas the other outcomes were not significantly different between the different groups (all $P>.05$ ) (Table 2).

\section{Procedure-Associated Adverse Events}

The overall rate of the adverse events noted in the study was significantly lower in the AT group compared with that of the SRT group (52.5\% versus 72.5\%; OR 0.42 [95\% CI, 0.19-0.95], $P=.035)$, with the exception of malignant cerebral edema (10.0\% versus $27.5 \%$; OR 0.29 [95\% CI, $0.09-0.93$ ]; $P=.05$ ). The rates of any $\mathrm{ICH}$, symptomatic $\mathrm{ICH}$, or the downstream territory embolism were lower in the AT group compared with the SRT group. However, the differences were not significant. Similarly, the rate of all-cause mortality at the 90 -day time period was $15 \%$ in the AT group and $17.4 \%$ in the SRT group (OR 0.84 [95\% CI, 0.29-2.44]; $P=.746)$. In the PSM sample, the rate of ICH in the
AT group was significantly lower than that in the SRT group (20.0\% versus 46.7\%; OR 0.29 [95\% CI, 0.09-0.90], $P=.028$ ). However, with regard to the other adverse events, including the rate of mortality at the 90-day period, no significant differences were noted between the 2 groups (all $P>.05$ ) (Table 3 ).

\section{DISCUSSION}

The results of the present study indicated that the patients who presented within 16 hours of onset of terminal ICA occlusion and received treatment with direct AT as the preferred therapy exhibited a higher percentage of reperfusion, shorter PRT, and fewer ICH adverse events compared with the corresponding end points of the patients treated with preferred SRT. Although the eTICI $2 b-3$ rate was higher in the AT group, the results were not significantly different after PSM, which was similar to the results of the Contact Aspiration Versus Stent Retriever for Successful Revascularization (ASTER) and COMPASS Trial: a Direct Aspiration First Pass Technique (COMPASS) trials. ${ }^{6,7}$ However, in the present study, the rate of eTICI $2 c-3$ and eTICI 3 grade after the complete procedure was significantly higher in the AT 
Table 1: Baseline characteristics of raw and PSM data of the 2 groups

\begin{tabular}{|c|c|c|c|c|c|c|c|c|}
\hline & \multicolumn{4}{|c|}{ Overall Sample } & \multicolumn{4}{|c|}{ PSM Sample } \\
\hline & $\begin{array}{l}\text { AT Group } \\
(n=40)\end{array}$ & $\begin{array}{l}\text { SRT Group } \\
(n=69)\end{array}$ & OR $(95 \% \mathrm{CI})$ & $P$ & $\begin{array}{l}\text { AT Group } \\
(n=30)\end{array}$ & $\begin{array}{l}\text { SRT Group } \\
(n=30)\end{array}$ & OR $(95 \% \mathrm{CI})$ & $P$ \\
\hline Sex, male, $n(\%)$ & $21(52.5)$ & $28(40.6)$ & $1.62(0.74-3.54)$ & .228 & $13(43.3)$ & $11(36.7)$ & $1.32(0.47-3.72)$ & .598 \\
\hline Age, mean $\pm S D, y$ & $68.3 \pm 14.0$ & $69.5 \pm 9.2$ & NA & .631 & $69.2 \pm 14.0$ & $69.4 \pm 7.9$ & NA & .946 \\
\hline $\begin{array}{l}\text { Pre-NIHSS score, } \\
\text { median (IQR) }\end{array}$ & $21(15-23)$ & $19(16-22)$ & NA & .160 & $21(15-22)$ & $18(16-22)$ & NA & .342 \\
\hline \multicolumn{9}{|l|}{ Stroke etiology } \\
\hline Cardioembolic, $n(\%)$ & $37(92.5)$ & $57(82.6)$ & $2.60(0.69-9.82)$ & .248 & $28(93.3)$ & $25(83.3)$ & $2.80(0.50-15.73)$ & .421 \\
\hline $\begin{array}{l}\text { Large vessel } \\
\text { atherosclerosis, } \\
n(\%)\end{array}$ & $1(2.5)$ & $10(14.5)$ & $0.15(0.02-1.23)$ & .094 & $1(3.3)$ & $2(6.7)$ & $0.48(0.04-5.63)$ & .999 \\
\hline Other etiology, $n(\%)$ & $2(5.0)$ & $2(2.9)$ & $1.76(0.24-13.02)$ & .973 & $1(3.3)$ & $3(10.0)$ & $0.31(0.03-3.17)$ & .605 \\
\hline $\begin{array}{l}\text { Onset to puncture } \\
\text { time, median (IQR), } \\
\text { min }\end{array}$ & $288(180-480)$ & $240(169-314)$ & NA & .061 & $250(161-338)$ & $243(174-338)$ & NA & .859 \\
\hline $\begin{array}{l}\text { ASITN/SIRs grade, } \\
\text { median (IQR) }\end{array}$ & $2(1-2)$ & $2(1-2)$ & NA & .677 & $2(1-2)$ & $2(1-2)$ & NA & .839 \\
\hline $\begin{array}{r}\text { Baseline ASPECTS, } \\
\text { median (IQR) }\end{array}$ & $7(5-8)$ & $7(6-8)$ & NA & .110 & $7(5-8)$ & $6(5-7)$ & NA & .711 \\
\hline ASPECTS $<6, n(\%)$ & $12(30.0)$ & $27(39.1)$ & $0.67(0.29-1.53)$ & .338 & $9(30.0)$ & $11(36.7)$ & $0.74(0.25-2.18)$ & .584 \\
\hline
\end{tabular}

Note:-SD indicates standard deviation; IQR, interquartile range (25\%-75\%); NA, not applicable.

Table 2: Procedural details and clinical outcomes of the 2 groups

\begin{tabular}{|c|c|c|c|c|c|c|c|c|}
\hline & \multicolumn{4}{|c|}{ Overall Sample } & \multicolumn{4}{|c|}{ PSM Sample } \\
\hline & $\begin{array}{l}\text { AT Group } \\
(n=40)\end{array}$ & $\begin{array}{l}\text { SRT Group } \\
(n=69)\end{array}$ & OR $(95 \% \mathrm{CI})$ & $P$ & $\begin{array}{l}\text { AT Group } \\
(n=30)\end{array}$ & $\begin{array}{l}\text { SRT Group } \\
(n=30)\end{array}$ & OR $(95 \% \mathrm{CI})$ & $P$ \\
\hline eTICl 2b-3, n (\%) & $40(100)$ & $56(81.2)$ & $1.23(1.10-1.38)$ & .002 & $30(100)$ & $27(90.0)$ & $1.11(0.99-1.25)$ & .237 \\
\hline eTICI 2c-3, n (\%) & $34(85.0)$ & $38(55.1)$ & $4.62(1.72-12.43)$ & .001 & $26(86.7)$ & $15(50.0)$ & $6.50(1.82-23.21)$ & .006 \\
\hline eTICI 3, n (\%) & $29(72.5)$ & $32(46.4)$ & $3.05(1.32-7.06)$ & .008 & $22(73.3)$ & $11(36.7)$ & $4.75(1.58-14.25)$ & .004 \\
\hline $\begin{array}{l}\text { First pass to eTICl } 2 b-3, n \\
(\%)\end{array}$ & $10(25.0)$ & $15(21.7)$ & $1.20(0.48-3.00)$ & .696 & $9(30.0)$ & $9(30.0)$ & $1.00(0.33-3.02)$ & .999 \\
\hline $\begin{array}{l}\text { First pass to eTICl } 2 \mathrm{c}-3 \text {, } \\
n(\%)\end{array}$ & $10(25.0)$ & $12(17.4)$ & $1.58(0.61-4.01)$ & .340 & $9(30.0)$ & $6(20.0)$ & $3.05(1.00-3.93)$ & .044 \\
\hline First pass to eTICI $3, n(\%)$ & $8(20.0)$ & $11(15.9)$ & $1.32(0.48-3.61)$ & .590 & $8(26.7)$ & $5(16.7)$ & $1.82(0.52-6.38)$ & .347 \\
\hline $\begin{array}{l}\text { No. passes of } \\
\text { thrombectomy, median } \\
\text { (IQR) }\end{array}$ & $2(2-3.7)$ & $3(2-4)$ & NA & .900 & $2(1-3)$ & $2.5(1-3)$ & NA & .367 \\
\hline Rescue treatment, $n(\%)$ & $6(15.0)$ & $8(11.6)$ & $1.35(0.43-4.20)$ & .608 & $5(16.7)$ & $6(20.0)$ & $0.80(0.22-2.97)$ & .739 \\
\hline PRT, median (IQR) (min) & $46(24-68)$ & $83(55-120)$ & NA & .001 & $38(22-56)$ & $69(45-120)$ & NA & .001 \\
\hline $\begin{array}{l}\text { Onset to reperfusion time, } \\
\text { median (IQR) (min) }\end{array}$ & $355(222-550)$ & $337(264-420)$ & NA & .900 & $249(205-391)$ & $344(248-450)$ & NA & .145 \\
\hline Use of rtPA, $n(\%)$ & $12(30.0)$ & $33(47.8)$ & $0.47(0.21-1.07)$ & .068 & $11(36.7)$ & $15(50.0)$ & $0.58(0.19-1.59)$ & .297 \\
\hline $\begin{array}{l}\text { Administration of GPI, } \\
n(\%)\end{array}$ & $2(5.0)$ & $10(14.5)$ & $0.31(0.06-1.50)$ & .227 & $1(3.3)$ & $3(10.0)$ & $0.31(0.03-3.17)$ & .605 \\
\hline $\begin{array}{l}\text { Balloon angioplasty, } \\
n(\%)\end{array}$ & $1(2.5)$ & $2(2.9)$ & $0.86(0.08-9.78)$ & .999 & $1(3.3)$ & $2(6.7)$ & $0.48(0.04-5.63)$ & .999 \\
\hline Stent placement, $n(\%)$ & $0(0)$ & $5(7.2)$ & $0.33(0.04-2.91)$ & .156 & $0(0)$ & $2(6.7)$ & 1.07 (0.97-1.18) & .492 \\
\hline IV heparin, $n(\%)$ & $28(70.0)$ & $36(52.2)$ & $2.14(0.94-4.88)$ & .068 & $19(63.3)$ & $15(50.0)$ & $1.73(0.62-4.85)$ & .297 \\
\hline $\begin{array}{l}\text { mRS score } 0-1 \text { at } 90 \text { days, } \\
n(\%)\end{array}$ & $13(32.5)$ & $15(21.7)$ & $1.73(0.72-4.16)$ & .215 & $11(36.7)$ & 5 (16.7) & $2.90(0.86-9.75)$ & .080 \\
\hline $\begin{array}{l}\text { mRS score } 0-2 \text { at } 90 \text { days, } \\
n(\%)\end{array}$ & $17(42.5)$ & $22(31.9)$ & $1.92(0.86-4.25)$ & .265 & $15(50.0)$ & $9(30.0)$ & $2.33(0.81-6.73)$ & .114 \\
\hline $\begin{array}{l}\text { mRS score } 3-5 \text { at } 90 \text { days, } \\
n(\%)\end{array}$ & $17(42.5)$ & $35(50.7)$ & $0.72(0.33-1.57)$ & .407 & $10(33.3)$ & $16(53.3)$ & $0.44(0.15-1.24)$ & .118 \\
\hline
\end{tabular}

Note:-NA indicates not applicable; GPI, glycoprotein IIb/IIla receptor inhibitor.

group $(P=.008)$, even after PSM $(P=.004)$. This may be associated with the thrombectomy techniques. The aspiration catheter did not cross the occluded segment in the AT group, which would not disrupt the thrombus. Consequently, the thrombus would be totally removed. During SRT, the stent retriever may disrupt the thrombus and cause embolization to the downstream territory.

Thrombectomy of these downstream territories was not attempted if an eTICI $2 \mathrm{~b}$ or higher was achieved. Therefore, the proportion of the subjects who achieved eTICI 3 was significantly 


\section{expanded Thrombolysis In Cerebral Infarction (eTICI)}

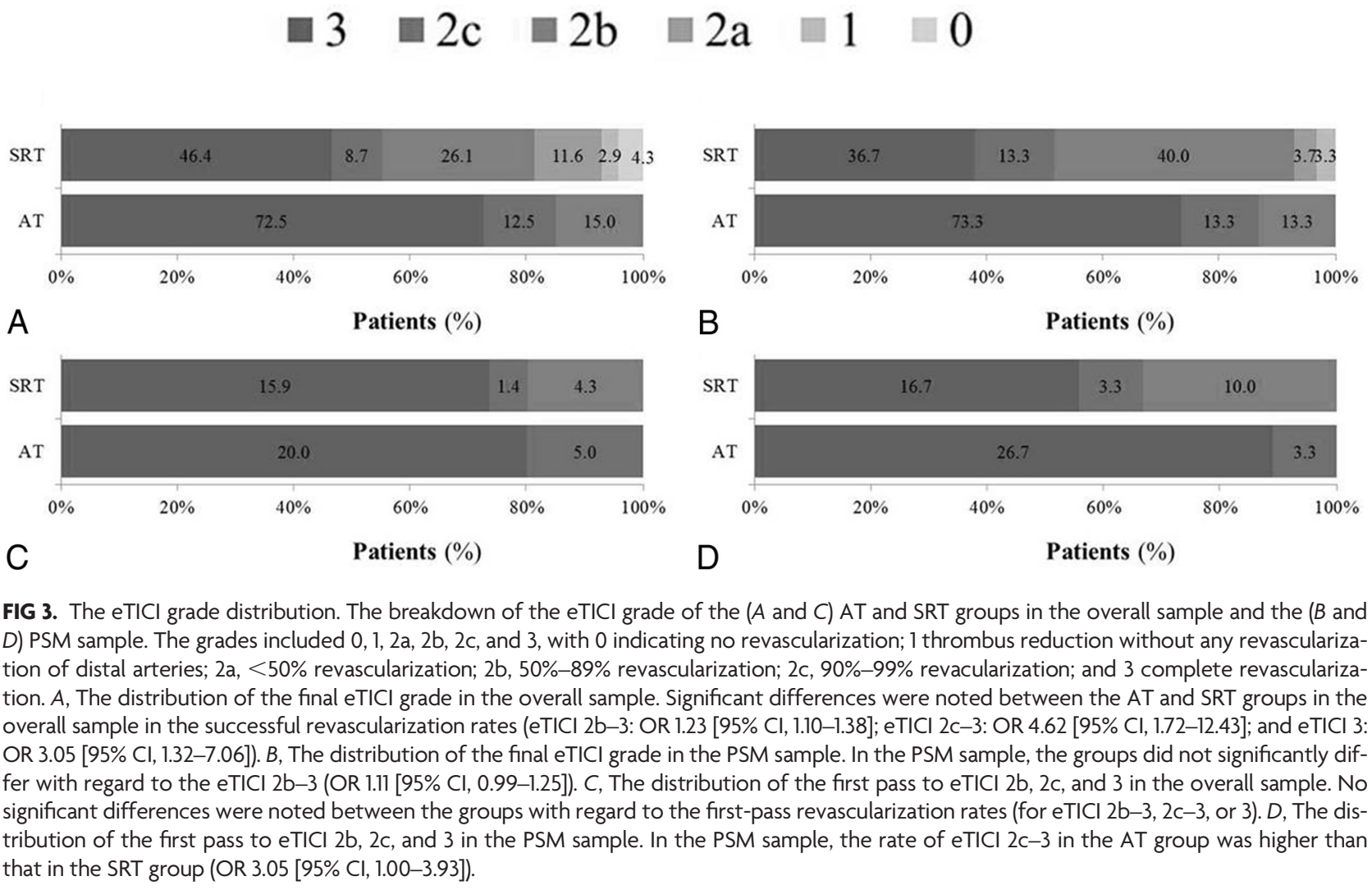

Table 3: Adverse events after mechanical thrombectomy in the 2 groups

\begin{tabular}{|c|c|c|c|c|c|c|c|c|}
\hline & \multicolumn{4}{|c|}{ Overall Sample } & \multicolumn{4}{|c|}{ PSM Sample } \\
\hline & $\begin{array}{c}\text { AT Group, } \\
n(\%) \\
(n=40)\end{array}$ & $\begin{array}{l}\text { SRT Group, } \\
n(\%)(n=69)\end{array}$ & OR $(95 \% \mathrm{Cl})$ & $P$ & $\begin{array}{c}\text { AT Group, } \\
n(\%) \\
(n=30)\end{array}$ & $\begin{array}{l}\text { SRT Group, } \\
n(\%)(n=30)\end{array}$ & OR $(95 \% \mathrm{Cl})$ & $P$ \\
\hline Overall adverse events & $21(52.5)$ & $50(72.5)$ & $0.42(0.19-0.95)$ & .035 & 14 (46.7) & 20 (66.7) & $0.44(0.15-1.24)$ & .118 \\
\hline Any ICH & $12(30.0)$ & $28(40.6)$ & $0.63(0.27-1.44)$ & .269 & $6(20.0)$ & $14(46.7)$ & $0.29(0.09-0.90)$ & .028 \\
\hline Symptomatic ICH & $4(10.0)$ & $14(20.3)$ & $0.44(0.13-1.43)$ & .260 & $3(10.0)$ & $8(26.7)$ & $0.31(0.07-1.29)$ & .182 \\
\hline $\begin{array}{l}\text { Downstream territory } \\
\text { embolism }\end{array}$ & $17(42.5)$ & $31(44.9)$ & $0.91(0.41-1.99)$ & .806 & $11(36.7)$ & $11(36.7)$ & $1.00(0.35-2.86)$ & .999 \\
\hline Malignant cerebral edema & $4(10.0)$ & $19(27.5)$ & $0.29(0.09-0.93)$ & .050 & $4(13.3)$ & $5(16.7)$ & $0.77(0.19-3.20)$ & .999 \\
\hline All-cause mortality at 90 days & $6(15.0)$ & $12(17.4)$ & $0.84(0.29-2.44)$ & .746 & $6(20.0)$ & $6(20.0)$ & $1.00(0.28-3.54)$ & .999 \\
\hline
\end{tabular}

higher in the AT group, which was similar to the results noted in the COMPASS trial. ${ }^{7}$ Although the results were contrary to the ASTER trial, ${ }^{6}$ the rate of eTICI 3 in the present study was higher than that noted in the AT and SRT groups of the ASTER trial. ${ }^{6}$ However, this difference did not improve the favorable outcomes (mRS score, 0-2) noted at the 90-day period and no significant differences were noted in both the overall sample and in the PSM sample. The rates of mRS score of 0-2 in the AT and SRT groups were lower than those noted previously, which may be associated with the occluded location. ${ }^{6-9}$ Although no significant differences were noted between middle artery occlusions and ICA occlusions, the patients with ICA occlusions exhibited poor clinical outcomes. ${ }^{1,12,13}$ Moreover, the terminal ICA occlusion was considered to occur with lower complete recanalization in the presence of a single thrombectomy device pass that renders it resistant to current techniques. ${ }^{14}$

The rates of the first pass to eTICI $2 b-3,2 c-3$, and 3 were similar in the overall samples (all $P>.05$ ), whereas the rate of the eTICI $2 \mathrm{c}-3$ was higher after PSM $(P=.044)$ in the AT group compared with that of the SRT group. These effects were lower than those noted in the ASTER and COMPASS trials, ${ }^{6,7}$ which included a higher proportion of MCA occlusions. Unlike SRT, AT enables the successful removal of the thrombus when the aspiration catheter is in contact with the core of thrombus. If the catheter does not contact the core of the thrombus, then the latter will not be removed. Therefore, a higher rate of rescue treatment was observed in the AT group, though the differences were not significant in the overall 
sample $(P=.608)$ and the PSM sample $(P=.739)$. Nonterminal ICA occlusion was an independent predictor of achieving complete recanalization with a single thrombectomy device pass. ${ }^{14}$

An additional reason for observing a lower rate of the eTICI $2 c-3$ after the application of all the procedures and the first pass to eTICI $2 \mathrm{c}-3$ in the SRT group may be attributed to the absence of the BGC. This device was considered an independent predictor of the first-pass effect success rate from a single thrombectomy device as well as a predictor of recanalization success and optimal clinical outcomes. ${ }^{15-19}$ Although it has been recommended as a routine adjuvant technique for stent retrieval by several studies, ${ }^{5,20}$ considerable controversy exists, notably when the distal access catheter is used in conjunction with the stent retriever, which may facilitate distal aspiration and minimize the impact of the absence of a BGC. ${ }^{6}$ BGCs were not available during the study in our center. Instead, $8 \mathrm{~F}$ guide catheters were contacted with a $60 \mathrm{ml}$ syringe both in the AT and SRT groups during thrombectomy, and intermediate catheters were used as a routine for distal aspiration in conjunction with stent retrievers in the SRT group. The absence of a BGC may have reduced the rate of the eTICI $2 \mathrm{~b}-3$ in the present study, notably in the SRT group. However, the final successful recanalization rates noted both in the AT and SRT groups were not inferior to the results obtained when using a BGC. ${ }^{15,16}$ Although results of one study indicated that the use of a BGC was significantly superior to the application of the distal access catheter, the higher baseline ASPECTS demonstrated lessfrequent ICA occlusions in the BGC group that could lead to significant bias of the results. ${ }^{15}$

The median PRT in the AT group was significantly lower than that of the SRT group in the overall sample $(P=.001)$ and the PSM sample $(P=.001)$. This may be associated with reduced time caused by the lack of crossing over the occluded segment and opening the stent retriever in the AT group. In the presence of the direct AT, the catheter simply requires contact to the proximal surface of the thrombus and does not need to fully cross the occluded segment, as noted for SRT. This finding is in agreement with the results of the COMPASS trial and those reported from relevant meta-analysis studies. ${ }^{7-9}$ In the present study, AT was selected as the first-line thrombectomy approach for patients with a longer time of onset. Therefore, the AT group exhibited longer median onset to puncture time, though, when PSM was applied, the results were not significant $(P=.859)$. The advantages of shorter PRT in the AT group were balanced by the longer onset to puncture time. Therefore, the median onset to reperfusion time was similar in the AT and SRT groups after PSM ( $P=$ .145). The similar values obtained in the onset to reperfusion time were associated with optimal outcomes. ${ }^{21,22}$ This could explain the similarity in these results noted at the 90-day period between the groups with comparable basic characteristics after PSM, including age, pre-NIHSS score, stroke etiology, and collateral circulation. In this study, AT was more efficient than SRT due to fewer passes and less operative time during the procedure. This advantage was not balanced by the application of rescue treatment; the latter proportion in the AT group was higher than in the SRT group in the overall sample but lower in the PSM sample.
The favorable outcome incidence at the 90-day period was $40.0 \%(24 / 60)$ after PSM, which was lower than the results obtained in the Highly Effective Reperfusion evaluated in Multiple Endovascular Stroke Trials (HERMES) collaboration (46.0\%) and in the current meta-analysis (45.9\%-49.0\%)., ${ }^{8,9,23}$ The all-cause mortality noted at the 90 -day period after PSM was $20.0 \%(12 / 60)$, which was higher than that noted in most the published studies with the exception of the COMPASS trial. $^{6-9,23}$ The poor outcomes noted and the higher mortality were possibly associated with the occluded location. The natural history terminal ICA occlusion was extremely poor without reperfusion therapy, even after endovascular treatment. ${ }^{2,24}$ Although no significant differences were noted between outcome and mortality between the different groups, the overall rate of adverse events was lower in the AT group. Moreover, the rate of any ICH incidence after PSM was lower in the AT group $(P=.001)$.

Although PSM analysis was used to minimize the case selection bias and the impact of confounding variables, the present study still exhibited several limitations. First, the absence of a BGC was one of the major limitations, despite the presence of alternative strategies. Second, despite the use of the aspiration by an intermediate catheter (distal access catheter) in the SRT group, the aspiration was performed only during stent-retriever withdrawal. The adjustments in the timing of aspiration utilization with SRT (eg, in the CAPTIVE [Continuous Aspiration Prior to Intracranial Vascular Embolectomy] technique) may improve the reperfusion rate of the terminal ICA occlusions. ${ }^{25}$ This could be a topic of future research. Third, it was a retrospective study that spanned nearly 5 years. The changes of surgical experience, materials, and imaging methods may reflect the outcomes. Moreover, the low sample size did not allow subgroup analysis due to the clot burden score, clot length, or different types of ICA occlusions, which may be associated with different outcomes. Fourth, the core infarct size was not evaluated in patients treated within 6 hours. Moreover, some patients with large-sized core infarctions (such as ASPECTS < 6) treated with mechanical thrombectomy may decrease the proportion of favorable outcomes. They are considered unsuitable for endovascular treatment due to poor outcomes and a high incidence of symptomatic $\mathrm{ICH} .{ }^{26,27}$ Fifth, the absence of subgroup analysis due to the application of the device within the aspiration and the stent-retriever cohorts further limited the study design.

\section{CONCLUSIONS}

For acute ischemic stroke due to terminal ICA occlusion, the results demonstrated that the use of $\mathrm{AT}$ as the preferred treatment was technically superior to SRT without proximal flow arrest when using a BGC in achieving complete recanalization, shortening PRT, and reducing the rate of ICH events. Additional studies are required to validate our findings in the context of BGC-assisted SRT and to determine the optimal treatment strategy for terminal ICA occlusion.

\section{REFERENCES}

1. Liebeskind DS, Flint AC, Budzik RF, et al. Carotid I's, L's and T's: collaterals shape the outcome of intracranial carotid occlusion in 
acute ischemic stroke. J Neurointerv Surg 2015;7:402-07 CrossRef Medline

2. Kwak JH, Zhao L, Kim JK, et al. The outcome and efficacy of recanalization in patients with acute internal carotid artery occlusion. AJNR Am J Neuroradiol 2014;35:747-53 CrossRef Medline

3. King S, Khatri P, Carrozella J, et al. Anterior cerebral artery emboli in combined intravenous and intra-arterial rtPA treatment of acute ischemic stroke in the IMS I and II trials. AJNR Am J Neuroradiol 2007;28:1890-94 CrossRef Medline

4. Eesa M, Almekhlafi MA, Mitha AP, et al. Manual aspiration thrombectomy through balloon-tipped guide catheter for rapid clot burden reduction in endovascular therapy for ICA L/T occlusion. Neuroradiology 2012;54:1261-65 CrossRef Medline

5. Tonetti DA, Desai SM, Casillo S, et al. Stentriever salvage after failed manual aspiration thrombectomy. J Neurointerv Surg 2019;11: $747-50$

6. Lapergue B, Blanc R, Gory B, et al. Effect of endovascular contact aspiration vs stent retriever on revascularization in patients with acute ischemic stroke and large vessel occlusion: the ASTER randomized clinical trial. JAMA 2017;318:443-52 CrossRef Medline

7. Turk AS III, Siddiqui A, Fifi JT, et al. Aspiration thrombectomy versus stent retriever thrombectomy as first-line approach for large vessel occlusion (COMPASS): a multicentre, randomised, open label, blinded outcome, non-inferiority trial. Lancet 2019;393:9981008 CrossRef Medline

8. Phan K, Dmytriw AA, Teng I, et al. A direct aspiration first pass technique vs standard endovascular therapy for acute stroke: a systematic review and meta-analysis. Neurosurgery 2018;83:19-28 CrossRef

9. Tsang COA, Cheung IHW, Lau KK, et al. Outcomes of stent retriever versus aspiration-first thrombectomy in ischemic stroke: a systematic review and meta-analysis. AJNR Am J Neuroradiol 2018;39:2070-76 CrossRef Medline

10. Dargazanli C, Consoli A, Barral M, et al. Impact of modified TICI 3 vs modified TICI $2 \mathrm{~b}$ reperfusion score to predict good outcome following endovascular therapy. AJNR Am J Neuroradiol 2017;38: 90-96 CrossRef Medline

11. Flottmann F, Leischner H, Broocks G, et al. Recanalization rate per retrieval attempt in mechanical thrombectomy for acute ischemic stroke. Stroke 2018;49:2523-25 CrossRef Medline

12. Flint AC, Duckwiler GR, Budzik RF, et al. Mechanical thrombectomy of intracranial internal carotid occlusion: pooled results of the MERCI and Multi MERCI part I trials. Stroke 2007;38:1274-80 CrossRef Medline

13. Protto S, Sillanpää N, Pienimäki JP, et al. Stent retriever thrombectomy in different thrombus locations of anterior cerebral circulation. Cardiovasc Intervent Radiol 2016;39:988-93 CrossRef Medline

14. Zaidat OO, Castonguay AC, Linfante I, et al. First pass effect: a new measure for stroke thrombectomy devices. Stroke 2018;49:660-66 CrossRef Medline
15. Zaidat OO, Mueller-Kronast NH, Hassan AE, et al. Impact of balloon guide catheter use on clinical and angiographic outcomes in the STRATIS Stroke Thrombectomy Registry. Stroke 2019;50:697704 CrossRef Medline

16. Baek JH, Kim BM, Kang DH, et al. Balloon guide catheter is beneficial in endovascular treatment regardless of mechanical recanalization modality. Stroke 2019;50:1490-96 CrossRef Medline

17. Brinjikji W, Starke RM, Murad MH, et al. Impact of balloon guide catheter on technical and clinical outcomes: a systematic review and meta-analysis. J Neurointerv Surg 2018;10:335-39 CrossRef Medline

18. Stampfl S, Pfaff J, Herweh C, et al. Combined proximal balloon occlusion and distal aspiration: a new approach to prevent distal embolization during neurothrombectomy. J Neurointerv Surg 2017; 9:346-51 CrossRef Medline

19. Nguyen TN, Malisch T, Castonguay AC, et al. Balloon guide catheter improves revascularization and clinical outcomes with the Solitaire device: analysis of the North American Solitaire Acute Stroke Registry. Stroke 2014;45:141-45 CrossRef Medline

20. O'Neill D, Griffin E, Doyle KM, et al. A standardized aspiration-first approach for thrombectomy to increase speed and improve recanalization rates. AJNR Am J Neuroradiol 2019;40:1335-41 CrossRef Medline

21. Hwang YH, Kang DH, Kim YW, et al. Impact of time-to-reperfusion on outcome in patients with poor collaterals. AJNR Am J Neuroradiol 2015;36:495-500 CrossRef Medline

22. Kim BM, Baek JH, Heo JH, et al. Collateral status affects the onsetto-reperfusion time window for good outcome. J Neurol Neurosurg Psychiatry 2018;89:903-09 CrossRef Medline

23. Goyal M, Menon BK, Zwam WH, et al. Endovascular thrombectomy after large-vessel ischaemic stroke: a meta-analysis of individual patient data from five randomised trials. Lancet 2016;387: 1723-31 CrossRef Medline

24. Hernández-Pérez M, Pérez de la Ossa N, Aleu A, et al. Natural history of acute stroke due to occlusion of the middle cerebral artery and intracranial internal carotid artery. J Neuroimaging 2014;24: 354-58 CrossRef Medline

25. McTaggart RA, Tung EL, Yaghi S, et al. Continuous aspiration prior to intracranial vascular embolectomy (CAPTIVE): a technique which improves outcomes. J Neurointerv Surg 2017;9:115459 CrossRef Medline

26. Kimura K, Iguchi $Y$, Shibazaki $K$, et al. Large ischemic lesions on diffusion-weighted imaging done before intravenous tissue plasminogen activator thrombolysis predicts a poor outcome in patients with acute stroke. Stroke 2008;39:2388-91 CrossRef Medline

27. Hao $\mathrm{Y}$, Yang D, Wang $\mathrm{H}$, et al. Predictors for symptomatic intracranial hemorrhage after endovascular treatment of acute ischemic stroke. Stroke 2017;48:1203-09 CrossRef Medline 